\title{
The Digital Divide: An Inquiry from Feminist Perspectives
}

Lina Gurung

\begin{abstract}
Exponential use of ICT has brought colossal opportunities as well as challenges to the present society. In spite of increasing women's involvement in Information, Communication and Technology (ICT), gender inequality has yet remained critical across the nations and globe. The uneven access and skills to technology has intensified the degree of digital divide specially for the women. Further the multifaced attribute of ICT and its relation with women is changing discourses among the feminist scholars. This is a conceptual paper which focuses on the deliberations of different feminists based on optimistic and pessimistic perspectives. Some studies show that the gender digital divide is getting intense while some have reported of alleviating gaps with more involvement of women. The concept of digital divide is beyond the access and includes various dimensions such as perception, usage, motivation, participation and skills. The paper deals with the tension between utopian and dystopian views on technology benefits. Through literature review this conceptual paper examines and discusses the diverse standpoints of feminist scholars from west and east which buzzes to redefine the relationship of gender with technology. It recommends that empowerment of women in technological domain is equally important as social, economic and political. Further women should be motivated from within to embrace ICT and get benefitted from its prospects. Resisting modern technology in the digital era would further widen the digital gap and thus make difficult to observe gender equality. More studies are required to explore the strategies for technological empowerment of women.
\end{abstract}

Keywords : digital divide, gender, technological empowerment, women and ICT, women and technology

\section{Introduction}

There have been innumerous efforts globally for achieving the status of gender equality. Much of the focus has been given to women's economic, political and social empowerment. Though it has been realized that women's involvement in using and designing new technologies can empower them socially and economically (Masika \& Bailur, 2015), the gender issues in ICT has been largely ignored (Barua \& Barua, 2012). The gender inequality has yet remained critical across the world. For this purpose, the inclusion of women's concerns in all aspects of ICT, the increase of women's interaction with ICT through the academic sector and the recognition of the women's agency in the ICT workforce remains vital. There is an increasing participation of women in the public workforce but still there is under-representation of women within the ICT sector. And many studies show that the situation is even more pitiful in science and technology. There is a need for analyses of the unexplored relationship between gender and ICTs and its theorization.

Due to the need to balance the technological development across the world, the concept of the digital divide has drawn much attention and mostly the research is focused on accessibility of technology and the level of penetration based on geographic area but there has been less research on the reasons behind such a digital divide (Abu-Shanab \& Al-Jamal, 2015). As we agree that the world is getting smaller due to various technological innovation, it is also equally true that this is reinforcing the divide of haves and haves-not with access to these technologies.

Hibert (2009) defines the term 'digital divide' as the divide between those included and those excluded from the digital age, leaving lots of room for interpretation. It also refers to "situations in which there is a marked gap in access to or use of ICT devices' (Campbell 2001 as cited in Alampay, 2006). According to Abu-Shanab \& AlJamal (2015), digital divide is about the unequal access of people to ICT and unequal possession of skills and experiences needed to optimize this technology. While we embrace the prospects of technological benefits, it has simultaneously deepened the complexity of society through social exclusion and relegation of some portion of human population in the world. Thus, global digital divide denotes the pattern of uneven distribution of ICT benefits worldwide (Pande \& Weide, 2012). However, this is just a single approach to see the situation. But it is even more complicated when it comes about the various crosscutting aspects in the digital divide such as gender. The analysis of gender aspects in ICT is even tough due to the unavailability of official statistics especially in the developing countries (Abu-Shanab \& Al-Jamal, 2015). Further the wide discourse of gender issues in the virtual world has been constrained by various factors which have been explained from multiple perspectives from different strands of feminism. It has drawn attention for research on the exclusion of women from the conventional histories 
of western science and technology. There is also changing discourse on the relationship of women with technology or ICT. Rydhagen (2004) argues that as long as the digital divide is defined as lack of access to information to consumers, the only remedy would be of supplying ICTs for the sake of giving information and the interactive relations would be overshadowed. I think this is more important when gender comes as crosscutting issue to the ICT access, usages, perception and benefits distribution.

The study of gender and ICT is dynamic as its role and ICT usages are constantly changing where men and women enter into new relationships with it (Lie, 2003). So, the relationship between women and ICT is not stable. The digital divide has widened in some places while it is shrinking in others. There are optimistic as well as pessimistic users. The utopian and dystopian discourse of the benefits of engagement with ICT is getting even intense. There is varying explanation of feminists making this issue more thought-provoking. It is even more stimulating in regard to the academia with the ICT integrated teaching, learning and delivery system. ICT as a panacea or rupture is therefore the established as well as unstable concepts that stimulates the ICT users, designers, researchers and philosophers.

My aim in the paper is to highlight the contemporary and emerging discourse of ICT and women from the diverse theoretical lenses as put forward by different feminists. In this paper I have reviewed the scholarly work of variety of scholars with differing concerns in the relationship of gender and ICT. The analysis of the paper is based upon the foundation standpoints of feminists like Donna Haraway, Chandra Mohanty, and Judy Wajcman. Their viewpoints are discussed either within the pessimistic or optimistic arguments of the relation. The complementing and contrasting viewpoints from these feminists in relation to gender and ICTs has been logically discussed within two categories; utopian or dystopian perspectives on role of ICT. The postcolonial feminist perspectives have been specially discussed for dystopian views. Haraway is the influential and mostly cited feminists when it comes to discuss about gender dimensions in ICT. Wajcman (2007) adds to the optimistic ideas of empowering women through ICT. So their views counts an important remark while discussing the situation of gender and technology. At the same time the notions of postcolonial feminists; Mohanty has been skeptical and posed certain dystopian way of thinking. The postcolonial feminists opined of western culture devaluing women's experience and concerns (Barua \& Barua, 2012). The postcolonial feminists are skeptical of improving the lives of women by embracing technology. So, this contextual feminist lens can contribute to extending terrain of the discourse.

Rethinking the relationship between ICT and gender is important for the new knowledge production. Largely this paper discusses these feminists' lens while understanding about the gender and ICT. This understanding of relation in particular to 'gender digital divide (GDD) is basically about the artefacts, access, usages, perception and beliefs observed among men and women. So, it is not only the one-sided perspective but rather intends to draw attention to the changing paradigm of debates. In the paper my focus of the article is women as they are the most disadvantaged group in comparison to men being aware that gender is not only about women. To emphasize the situation of GDD, I have presented some empirical studies in global context. Then I have highlighted the relationship of gender and technology. The discussion of the feminist scholars' viewpoints is done under two sections as utopian and postcolonial feminist perspectives.

\section{Global context of Digital Divide}

Technology has become the integral part of development. There is no doubt that our way of thinking, exploring opportunities; developing skills and living a daily life have been reshaped by technology. In general, technology is considered as a part of ICT which involves more of computers, networking and equipment in managing information or related to company productivity. ICT can be seen in broader terms essentially inclined to the education arena such as online learning, virtual world, blogging, cyber use, techno-pedagogy and many such. These digital technologies irrespective of its technical aspects or use in educational settings, are meant at aiding individual and institution to access and manage information that could bring more repercussions in various level. These influences to everyday life from the gender perspectives is the emphasis discussed here. The recognition of 'technology' in this discourse is much more than the applied science and has provided broader approach enabling the feminists to redefine the boundaries of women's contribution to technology (Rowbotham, 2017). A technology is taken as 'force which has magnitude and direction, leading society towards certain directions rather than others' but though ICT is broadly defined could be also used in flexible ways (Gulbransen, Nsengiyumva, Rydhagen\&Trojer, 2004). In this regard, I acknowledge the interference of ICT and technology to our daily life and have alternatively as well as equally used the term 'technology' and 'ICT' with an intention to push its boundary beyond the conventional ways of understanding.

The conventional way of living, illiteracy, poverty, spatial difficulties, political marginalization are mostly responsible for their deprivation from technology. UNDP (1999) has noted: "The network society is creating parallel communications systems: one for those with income, education and literacy connections, giving plentiful information at low cost and high speed: the other are those without connections, blocked by high barriers of time, cost and uncertainty and dependent upon outdated information" (as cited in Quibria, Ahmed, Tschang \& Macasaquit, 2003, p. 63). Though it has been argued that ICTs assist in poverty alleviation (Duncombe, 2001 as cited in Alampay, 2006), all the people do not have equitable access which widens the poverty gap instead. There has been uneven distribution of ICT benefits and opportunities across the nations, region, class and gender.

Comparatively the situation of digital divide is not same 
worldwide. And various empirical studies show that uneven distribution of ICT is mostly seen among the marginalized people and women. There is less women working in ICT profession too. It is estimated $19 \%$ of women working in ICT occupations in UK which is a developed nation (Moore, Griffiths, Richardson and Adam, 2008). The study carried out in UK and Canada revealed that there is highly gendered division of labour in the ICT workplace perpetuating the stereotypes of hegemonic masculine computer culture. Though there has been witnessed of tremendous progress in female education in the Arab Gulf region, women are still at higher risk of being marginalized from today's knowledge-based economy due to unequal access to training, lack of awareness and traditionally male domination in ICT sector (Elnaggar, 2007). The study conducted among women in Oman found out that $44 \%$ of women were digitally illiterate, less than $32 \%$ of them had computers in their home and only $45 \%$ of them were using their PC (ibid) The penetration of mobile technology has made the life much easier irrespective of gender. However, using computers and internet, owning the digital skills for qualification upgrading and professional growth is found less utilized by women. And this creates a gap or divide in the current digital era.

In Bangladesh, women face discrimination, harassment, injustice and unequal treatment in society and use of ICT has been taken as a way to break their own barriers, exclusions and silences (Chaudhary, 2009). Chaudhary (2009) states that in spite of ICT being a tool of empowerment to change women's daily lives, only about $20 \%$ women are internet users of total population in Bangladesh. A recent survey (Rashid, 2016) with around 5000 respondents who use public access ICT venues from Bangladesh, Brazil, Chile, Ghana and the Philippines found that women in Bangladesh are more likely to suffer from digital exclusion compared to the other countries. It also showed that this digitally excluded women had significantly lower socioeconomic status especially owning low level of education and low ICT skills.

In 1996, the Norwegian University of Science and Technology in Trondheim, Norway conducted an advertising campaign and developed new module called 'know your subject' to include more female students to their computer science engineering program. The campaign highlighted certain characteristics of women highlighting their good communication skills, being social and problemoriented to blow away the myth of computer engineers suited for men only. Though more female students enrolled in the program, they were not happy to have found the program overly rationalist modelling techniques, lack of concern for users and thus their expectations were not met (Gansmo, Lagesen \& Sørensen, 2003).

These findings show that women are under-presented in ICT in both developed and developing countries. The problem of unequal access and use of ICT by women is more intense in developing countries. And it has been mostly due to deep-rooted patriarchal norms in the society. There is a huge gap between women's and men's access to telecommunications infrastructure which is largely concentrated in urban areas while the majority of women in the developing world are located in remote and rural areas (Moolman, Primo \& Shackleton, 2007).

Some developing countries claim of the increasing number of women's participation in technology justifies the rational of using ICT. In Malaysia, women comprise 44\% of professionals and $38.9 \%$ of technicians and associate professionals (Mellström, 2009). A study of Bangalore and Delhi found that women's involvement in IT industry and adoption to its nature of the work, it has resulted to positive outcomes such as enhanced agency and capacity within women to take decisions (Kelkar et al., 2002 as cited in Gupta, 2015).

Besides having the wide discourse on the access of women in technology, the debates have been shifted beyond looking to the usage, perception and capability of women while interacting with ICT tools. Rashid (2016) argues that having access to an ICT tool does not confirm that one uses it meaningfully as there are many complex dimensions, resources, relationships and structures that matters and must be taken into account. Dijk and Dueursen (2014, p.1) adds to this point and says that the divide of physical access might be alleviating but other forms of digital divide has begun to grow which have deepened this divide. They have suggested that digital skills are the key strategies to adaptation of new technologies that includes a person completely in the digital society.

One of the major prerequisite skill for getting benefits from ICT is the digital literacy. The general literacy has been shifted towards more specialization such as digital literacy. And general literacy is a precondition for digital literacy so to bridge the digital divide. Barton (2007, p.35) speaks of literacy as a part of our thinking and technology for thought. It carries social meanings. According to Barton (2007, p.34), "people make sense of literacy as social phenomena and their social construction of literacy lies at the root of their attitudes, their actions and their meanings". And this equally implies to digital literacy. Especially when developing countries are struggling hard to meet the general literacy among their people, it seems quite ambitious goal to have digitally literate people. Digital literacy makes people quite efficient and competent to shift from one side to other for grabbing opportunities. At the same time demand of digital literacy has posed more challenges to the development goals of developing nations. When people are living in the conventional society, the use of digital skill has not been embraced or even felt the need of it. A study conducted in Nepal, has shown that introduction of ICT in offices could be the less priority where there was no need of modern tools for facilitating it (Malling, 2000). It identified that the main use of ICTs was developed to meet the needs in the west for this externalization of meaning.

\section{Gender and Technology}

Though the access of the ICT among the women has been increased, technology is most likely being shaped by gender or could be vice versa (Oudshoorn, Saetnan, \& 
Lie, 2002). The use of technology and receiving benefits is also very much stimulated by our social values, gender roles and various stereotypes in our society (Buskens \& Webb, 2009). The gender gap, especially the gap between men and women and how they benefit from information technology has widened because women are less likely than men to receive technical education or be employed in technology intensive work (Pande \& Weide, 2012). So the GDD is part of a global evolving pattern and the problem is not only with access and use only but it has turned into complex as it depicts the social relations which are deepening the gender roles of the male dominated society. Technology is often associated with masculinity (Gupta, 2015, Wajcman, 2007; Faulkner, 2001; McQuillan\& Neill, 2009; Barua \& Barua, 2012). Gupta (2015) argues that less women are motivated in entering into IT professions due to the male friendly technology. However, in the digital era the women workforce in technology sector has increased. But this is not sufficient and more women are necessary to join the IT sector.

Faulkner (2001) has summarized Cockburn's claims of how technology is being gendered in seven ways. They are(a) Men are the key specialist actors of technological artifacts, (b) strong gender division of labour around technology, (c) technological artifacts being gendered materially and symbolically, (d) cultural images of technology associated with masculinity, (e) details of technical knowledge is gendered, (f) technical practice is being gendered and (g) gender identity is frequently premised on technology. Any artifacts are gendered when it is used either for men or women or associated with masculine or feminine aspects (Pilcher \& Whelehan, 2004, p. 59). Gendered artifacts can contribute to the maintenance of gendered social relations, especially relations of power (Oudshoorn, Saetnan, \& Lie, 2002). Therefore, the interactions between gender relations and technology is quite complex and entangled.

Employing social constructivist approach views, I believe that technology as being shaped by human action and interaction (Henry \& Powell, 2015). Constructivist scholars reject the view that artifacts are gender neutral objects designed according to the principles of technical function (Oudshoorn, Saetnana \& Lie, 2002). So the feminist studies of technology argues that the problem of digital gender gap is rooted in the social shaping of tradition (Leach \& Turner, 2015). This social shaping of tradition demonstrates its acquired social meaning of new technologies to their users and producers (Leach \& Turner, 2015). However, there are also arguments that the relationship between technology and gender is not static and challenges the universal applicability of computers associated with masculinity (Gupta, 2015). Therefore, the relationship between gender and technology changes over space and time (Gupta, 2015). It is important to know how women in developing countries adopts ICTs and empower themselves. Masika \& Bailur (2015) have termed it as 'adaptive preference' and 'patriarchal bargain' which is contextual and situated agency.

Different approaches and streams of Feminism explain the role of technology either in reproducing or challenging patriarchal norms. Thus they have both embraced and contested to the technological developments. Theorists have pointed out that women's alienation from technology in particular, is a product of the historical and cultural construction of technology as masculine (Cronin \& Roger, 1999). Faulkner (2000) identifies four streams of literature within the general area of gender-technology studies. He writes, "The first stream, "women in technology, "focuses on the role of women on the supply side of technology. The second stream, 'women and technology' takes as the point of departure the role of women as users of technology. The third stream, 'gender and technology' adds essentially a 'gender aware' layer of social constructivism on both technology and user dichotomy understood as gender dichotomy. The fourth emerging stream, which in a sense brings attention to the root phenomenon, is feminist studies on engineering practice, 'men/masculinity and technology'. These streams reflect societal developments such as the increasing role of women in the labor market and perhaps, also the paradigmatic developments within the generic field of gender-technology studies" (Faulkner 2000 as cited in Göransson, \& Rolfstam, 2013).

Lie $(2003$, p.15) has documented the changes from 1970s where computer skills were understood about knowing how computers work and its basic programming. Later in 1990s, the skills emphasized on the ability to access information and communicate via the screen leaving less priority to the hardware knowledge. According to Lie (2003, p.15), it was an important milestone stirring the need of interactive programs and communicative devices which changed the people's perception and the computers were redesigned.

Feminist theorists are now much more aware of both the contradictory effects of ICTs on women and the different meanings the same artefact might have for different groups of women (Wajcman, 2007). Feminist theories of gender and technology which has emerged over the last three decades has brought wider debates in the academia.

Cyber feminism that shares multiple aspects with second wave feminism began with strong techno-utopian expectations which they predicted would free women from the constraints of gender (Fernandez \& Wilding, 2003; Mc Quillan \& Neill, 2009). Although cyber feminism presents itself as inclusive, the writings of such assume an educated, white, upper middle-class, English speaking, culturally sophisticated readership which is being look ironically to damage the universalism of the old-style feminism (Fernandez \& Wilding, 2003). The postcolonial feminist Gayatri Spivak too even was often accused in the past of not representing the indigenous people of their region in spite of her strong advocating on women of third world. Therefore the debates among the cyber feminists and other feminists have boosted discourses of relationship between gender and technology.

\section{Utopian Perspectives}

Donna Haraway who was influenced by the Marxist ideas to some extend have written extensively about this issue. 
Donna Haraway is known for her radical feminist thoughts in science and technology. Haraway though call herself as 'unreconstructed marxist', supported the postmodernist view on technology as a potential source of empowerment for women (Henry \& Powell, 2015).

Haraway 'The Cyborg Manifesto' is the most important writing of her thoughts first published in 1985. Her groundbreaking work has been particularly influential among feminist techno-science scholars. In this piece of writing, she talks about 'Cyborg' which is a mythical creature produced by merging of man and machine. Haraway defines it as "A cyborg is a cybernetic organism, a hybrid of a machine and organism, a creature of social reality as well as a creature of fiction" (Haraway, 2015, p.149).

The concept of the cyborg is intended to encapsulate the extent to which advanced technological developments have blurred the boundaries between 'natural' and 'automated' human bodies (Pilcher, \& Whelehan, 2004, p.20). Cyborg aims at post-gendered man sharing joint kinship with animals and machines and at the same time, it prepares us to question the pure boundaries of gender and the human as opposed to the animal and the machine (Barua \& Barua, 2012). So, it represents the blurring line between biology and technology. Haraway says that myth and tool mutually constitute each other and if the cyborg theory is free of such myths on gendered power relations with ICT, it can stop to be a political language looking at science and technology. Consequently, it can challenge the informatics of domination with a better responsibility for social relations.

Judy Wajcman's (2010) contribution to this issue is a prominent one. She has examined the interrelationship of gender with technology in her influential book "Feminism Confronts Technology". In her book she mentioned that technology is both a source and cause of gender inequality (Wajcman, 2010). Several empirical studies have shown that the design, technical content and use of artefacts are profoundly influenced by the marginalization of women from the technological community (Wajcman, 2007). And marginalization is one of the existing features in our social structures especially in developing countries. Wajcman (2010) observed disinterest of women in ICT sector is due to the gender stereotyping with deeply engrained cultures of masculinity and women are asked to modify for a masculine version rather than 'degendering' the process for men. In terms of gender and ICTs, feminist scholars in science and technology studies has explored the effects of gender power relations on design and innovation as well as the impact of technological change on the sexes (Wajcman, 2007).

Haraways (2015) put forwards optimistic arguments about the opportunities that can bring radical political transformation if we embrace the development of techno science. This idea has infact brought new prospects in the feminist analyses and explore the ways how these technologies are entangled with our everyday life of women (Wajcman, 2010). Haraway opened up a new look by redefining and blurring the boundary between machines and animals which is believed to overcome the gender stereotypes (Barua \& Barua, 2012). Inspite of giving much emphasis on enforcement of situated knowledge, it did not inspire the other postcolonial scholars who had assumption of her ideas strengthen of modern scientific objectivity, putting women into the homogenous category and being monolithic. Critics states that "blurring of boundaries has not offered the African website producers new ways of expressing themselves, but instead imploded foreign and native to the advantage of foreign" (Gulbransen, Nsengiyumva, Rydhagen \& Trojer, 2004). Consequently, there were contesting ideas put forward strongly by postcolonial feminists which were of more pessimistic or dystopian views on the relationship of women and technology.

\section{Postcolonial Feminists Perspectives}

There has been critique of a western bias in gender and technology studies mostly by the postcolonial feminist who advocate for more context sensitivity and focus on the cultural embeddedness of gender and technology relations. The postcolonial feminists were against the generalization of ICT benefits in developing countries by western feminists. They have problematized the theories of communication saying that it largely rests upon a western, modernist perception which is unreflected and regarded universal (Shome \& Hegede, 2002 as cited in Gulbransen, Nsengiyumva, Rydhagen \& Trojer, 2004, p.49). In fact, the overall idea is not let to judge third world women into singular identity. Butler has argued that we cannot see women as unified homogenous group since every women is a unique individual (Barua \& Barua, 2012) and its national historical background matters too. So, while analyzing the relationship between gender and technology particularly with the perspectives of white women, the issue has much to offer a postcolonial critique.

The postcolonial perspective in the scientific and technological endeavors is pretty important to link the local and global context as well as its challenges (Anderson, 2002). There has been debates since long whether the technology is for or against the development of developing countries. The postcolonial scholars also seem critical of loss of their cultural identity due to the engagement with modern technology as there would be spread of cultural hegemony through ICT and the individualized culture would be dominant over the culture welfare. Rydhagen (2004) argues that empowering at individual level might cause a loss in collective and cultural terms. Henry and Powell (2015), states that "new technologies dismantle traditional constructions of gender and sexuality, which become increasingly irrelevant and /or multiple, diverse and shifting" (p.762). The postcolonial feminist has drawn attention to the diversity in culture, socioeconomic and ethnic position.

Chandra T. Mohanty's essential work 'under western eyes' (Mohanty 1986) aimed to articulate how western feminist scholarship helped to reproduce hierarchies of knowledge and identity among the women in developing countries. She wanted to discover and articulate a critique 
of 'western feminist' scholarship on third world women via the discursive colonization of the third world women's lives and struggles (Mohanty, 2003). She wanted specifically to challenge the Eurocentric universalizing methodologies that serve the interests of western women and show that feminist enquiry needed to focus on the micro-politics of local context and struggle, as well as the macro-politics of global political systems, something that much western scholarship has failed to address (Metcalfe \&Woodhams, 2012). Her idea was the foundation to stimulate the idea of criticizing the western technology. When it comes to technology use by women, it is suspected of its relativeness and need.

The postcolonial scholars are pessimistic about the relation between the political goal of equal access as put forward by the second wave feminism and the opportunities brought by the digital era (Gulbransen, Nsengiyumva, Rydhagen \& Trojer, 2004). These scholars question the basic principle about access in 'technology in a democratic society' and redirects the issue as 'democracy in an information society'.

Besides the foundational critics, there are varying opinions as well focusing on the need to redesign the technologies in the aspect of third world and making it contextual. There are provoking ideas of recognizing the potentiality of local people to interact, negotiate and adapt the technology to their own interest (Hongladarom, 2002 as cited in Gulbransen, Nsengiyumva, Rydhagen \& Trojer, 2004). Wang (1997) gives as example of rural population hanging to their own local music, drama, dance through the use of these technologies (as cited in Gulbransen, Nsengiyumva, Rydhagen \& Trojer, 2004). This depicts the picture that a complete resistance to the modern technology is unfeasible irrespective of the rural or urban area, men or women. As there is digital divide, there has to be digital inclusion too in a democratic society cheering the diversity and non-oppressive relationships. So now the question is not 'whether technology is good or bad' but it's the different purposes that defines its utility. So if we examine the utility of tools and capability of the users from our own local perspectives, the boundaries of western and third world itself would be blurred.

\section{Conclusion}

ICT has brought to realization that sustainable development and gender equality is still far reaching goal without having women's overall meaningful participation in the emerging world of technology. There is no doubt that there is a need of women's increased participation in ICT domain. Gender stereotypes in ICT have resulted to women's hesitation in taking the technological profession especially in developing countries. Female education is tremendously progressing and thus it is contributing to bridge the digital gap across the gender. As ICT has its significant impact for education and overall development, women's know-how is equally demanding which has posed various challenges too. There are various studies across nations and regions regarding the barriers the women face and factors responsible for women's less representation in ICT. Reviewing of the literature reveals that there is a torn between utopian and dystopian visions for relationship of gender and technology. It is a tension between optimism and pessimism in the techno-science and gender stereotypes. Haraway supports for the utopian vision by urging to embrace the positive potential of technology for women's empowerment. But at the same time, she is sharply critical that women should favor techno-science rather than avoiding it in name of various stereotypes of artifacts and perceptions. But the postcolonial feminist perspectives have been found to be less utopian and optimistic. Their critics of Western ideology has also highlighted the relativity of ICT for women's empowerment. They discuss not only the barriers of women but also the gendered artefacts, postcolonial contexts and development aspects which poses challenges for adhering to the benefits of ICT for third world women.

Developments in digital technologies do call for some radical rethinking both of the processes of technological innovation (Wajcman, 2007). In support to this the perspectives of Haraway through her metaphor of 'cyborg' seems provoking for both men and women to be accountable of what they think about ICT. Technology has been gendered indeed but it can be again reconstructed as 'cyborgs' is blurring the existed dualisms and dichotomies. Therefore, I agree to the point of Faulkner (2001) that we cannot transform gender relations without engaging women in technology. It is the ultimate need to breakthrough the increasingly complex intertwining of gender and technology. Thus, the various approaches should emphasis on reconstruction and again mutual shaping of gender and technology. Critical thinking on the power relations will help us to refine our understanding on the relationship between ICT and gender and treat it in way that promotes gender equality by reducing the gender digital divide in physical, mind and social norms. Its true that women's deprivation from the benefits of technology shares a common problem over the world between men and women but it is contextual as well. Women of the third world experiences the intensity of digital exclusion and marginalization than women from developed nations. Nevertheless, socially constructed norms are changing. Men and women are equally getting responsible for their self-empowerment. The social construction of the relationship with technology has created myths, unveiled them and is trying to nullifying it.

There is diversity of standpoints among feminist scholars regarding gender related digital gap. Recognition of difference across gender and within women has expanded the understanding of differences for digital divide in the academia. It has been understood that the gendered artifacts are very much influential to the situation of gendered digital divide. There have been various empirical evidences presented in the paper. Haraway though focused on the significance of situations with respect to technology was much criticized of strengthening the scientific objectivity. Mohanty (1986) had been expressive of her dissatisfaction on the single dominant approach of these western feminists. So contradictory views exist. 
The gender digital divide is not only about the level of access but also the opportunities and developing our own skills. The enhanced capabilities in use of ICT is very crucial for the sustainable development. Women have equal share in this earth as men is highly responsibility to break through the stereotypes or myths and finds their space in the information society. Accusing men for occupying the space will only invite debates with no action. Empowerment of women in the technological domain is the current need of the digital age and as essential as socio-economic and political empowerment. The avoidance of the technology will deepen the divide rather than inclusion. Modern technology is a part of western culture and is subordinating women to some extent but at the same time it can be redefined as technology and the society are interwoven in mutual shaping processes. Presenting women only as victims is not the whole picture, women have embraced technology and become the agent of technological changes. So women themselves too should be motivated to encompass ICT in their daily life for equal footing with men. If not, they will be left behind. The changing relations with ICT have given rise to new perception, revised arguments and discussions. There is ongoing transformation in the belief, use and benefit sharing of technology in society. Resisting modern technology in the digital era would further widen the digital gap and thus difficult to observe gender equality. More local studies are required to understand this phenomenon and explore the strategies for technological empowerment of women.

\section{References}

Abu-Shanab, E. \& Al-Jamal, N. (2015). Exploring the gender digital divide in Jordan. Gender, Technology and Development. 19(1). 91-113

Alampay, E.A. (2006). Beyond access to ICTs: Measuring capabilities in the information society. International Journal of Education and Development using Information and Communication Technology (IJDICT). 2(3). 4-22.

Barton, D. (2007) (2nded.). Literacy: An introduction to the ecology of written language. Malden, Mass: Blackwell Publishing.

Barua, A. \& Barua, A. (2012). Gendering the digital body: women and computers. AI \& Soc. 27. 465-477

Buskens, I. \& Webb, A. (2009). African women and ICT: Investigating technology, gender \& empowerment. Ottawa, Canada: IDRC.

Chaudhary, N. (2009). The question of empowerment: Women's perspectives on their internet use. Gender, Technology and Development. 13(3). 341-363

Cronin, C. \& Roger, A. (1999). Theorizing progress: Women in science, engineering, and technology in higher education. Journal of Research in Science Teaching. 36(6). 637-661.

Elnaggar, A. (2007). The status of Omani women in the ICT sector. International Journal of Education and Development using Information and Communication Technology (IJEDICT). 3(3). 4-15
Faulkner, W. (2000). The power and the pleasure? A research agenda for "making gender stick" to engineers. Science, Technology, \& Human Values, 25(1), 87-119.

Faulkner, W. (2001). The technology question in feminism: A view from feminist technology studies. Women's Studies International Forum. 24 (1). 79-95

Fernandez, M. \& Wilding, F. (2003). Situating cyber feminisms. In. In, Fernandez, M., Wilding, F. \& Wright, M. M. (Eds.). Domain Errors! : Cyber feminist Practices. New York: Autonomedia.

Gansmo, H.J., Lagesen, V. A., \&Sørensen, K.H. (2003). Forget the hacker? A critical reappraisal of Norwegian studies of gender an ICT. In Lie, M. (Ed.). He, she and IT revisited: New perspectives on gender in the information society. Oslo: GyldendalAkademisk. 3468

Göransson, B. \&Rolfstam, M. (2013). Development and use of gender-specific technologies: evidence from China, Poland and Sweden. Gender, Technology and Development. 17(3). 281-312.

Gulbrandsen, E., Nsengiyumva, A., Rydhagen, B. \& Trojer, L. (2004). (Eds). ICT, Innovation systems and the role of universities in societal development - a postcolonial strain?Butare: National University of Rwanda Press Ltd.

Gupta, N. (2015). Rethinking the relationship between gender and technology: A study of the Indian example. Work, employment and society. 29(4). 661-672.

Haraway, D. J. (2015). Simians, cyborgs, and women: The reinvention of nature. New York: Rutledge

Henry, N. \& Powell, A. (2015). Embodied harms: gender, shame and technology-facilitated sexual violence. Violence against Women. 21(6). 758-779

Hilbert, M. (2009). When is cheap, cheap enough to bridge the digital divide? Modeling income related structural challenges of technology diffusion in Latin America. World Development. 38(5). 756-770

Leach, L. \& Turner, S. (2015). Computers users do gender: The co-production of gender and communications technology. Sage open. 1-14

Lie, M. (2003). He, She and IT revisited: New perspectives on gender in the information society. Oslo: GyldendalAkademisk.

Malling, P. (2000). Information systems and human activity in Nepal. Chrisanthi, A \& Geoff, W. (Eds). Information technology in context: Studies from the perspective of developing countries. Aldershot: Ashgate. 11-22.

Masika, R \&Bailur, S. (2015). Negotiating women's agency through ICTs: A comparative study of Uganda and India. Gender, Technology and Development. 19(1). 43-69.

McQuillan, H. \& O’Neill, B. (2009). Gender differences in children's internet use. Journal of Children and Media. 3(4). 366-378.

Mellström, Ulf (2009). The intersection of gender, race and cultural boundaries, or why is computer science in Malaysia dominated by Women? Social studies of science. 39(6). 885-907

Metcalfe, B.D. \&Woodhams, C. (2012). Introduction: 
New directions in gender, diversity and organization theorizing- Re-imagining feminist post-colonialism, transnationalism and geographies of power. International Journal of Management Reviews. 14. Pp. 123-140

Mohanty, C.T. (1986). Under western eyes: Feminist scholarship and colonial discourses. Boundary 2, 12(3). 333-358

Mohanty, C.T. (2003). 'Under western eyes' revisited: Feminist solidarity through anticapitalist struggles. Signs. 28(2). 499-535.

Moolman, J., Primo, N. \& Shackleton, S. (2007). Taking a byte of technology: women and ICTs. Agenda: Empowering Women for Gender Equity. 71. 4-14

Moore, K., Griffiths, M. Richardson, H. \& Adam, A. (2008). Gendered futures? Women, the ICT workplace stories of the future. Gender, Work and Organization. 15(5). 523-542

Oudshoorn, N., Saetnan, A. R. \& Lie, M. (2002). On gender and things: Reflections on an exhibition on gendered artifacts. Women's Studies International Forum. 25(4). 471-483

Pande, R. \&Weide, T.V. (2012). Globalization, technology, diffusion and gender disparity: Social impacts of ICTs. USA: IGI Global

Pilcher, J. \&Whelehan, I. (2004). 50 key concepts in gender studies. London: Sage Publication

Quibria, M.G., Ahmed, S.N., Tschang, T. \& ReyesMacasaquit, M. (2003). Journal of Asian Economics. 13. 811-825.

Rashid, A.T. (2016). Digital inclusion and social inequality: Gender differences in ICT access and use in five developing countries. Gender, Technology and Development. 20(3). 306-332

Rowbotham, S. (2017). Feminist approaches to technology: Women's values or a gender lens? In Mitter, S \& Rowbotham, S. (Eds.) Women Encounter Technology. Changing patterns of employment in the third world. New York: Taylor Francis. 44-69

Rydhagen, B. (2004). Postcolonial ICT - a continuum or a rupture? In, Gulbrandsen, E., Nsengiyumva, A., Rydhagen, B. \& Trojer, L. (Eds). ICT, Innovation systems and the role of universities in societal development - a postcolonial strain?.Butare: National University of Rwanda Press Ltd.

UNDP (1999). New technologies and the global race for knowledge." In Human Development Report. New York: United Nations Development Program

Van Dijk, J.A.G.M, \& Van Deursen, A.J.A.M. (2014). Digital skills: Unlocking the information society. New York: Palgrave Macmillan

Wajcman, J. (2007). From women and technology to gendered technoscience. Information, Communication \& Society. 10 (3). 287-298

Wajcman, J. (2010). Feminist theories of technology. Camridge Journal of Economic. 34. 143-152
Gurung, Lina is a PhD Scholar at Kathmandu University, School of Education (KUSOED). She worked in KUSOED as a faculty from 2012 to2015. Currently she is working as a gender coordinator in NORHED Project under KUSOED. Gurung is engaged in education sector as a teacher in school and higher education for almost two decades. Her research interest focuses on online and distance education, women and Information Communication and Technology, women and media, feminist pedagogy, Girls' education and Indigenous culture studies.

Email: lina@kusoed.edu.np 